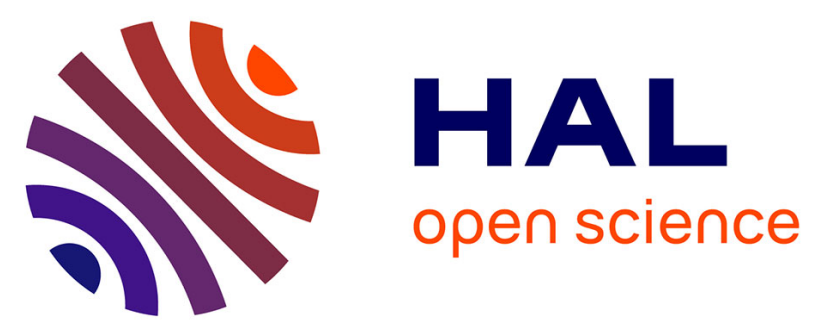

\title{
CALCULATED COMPTON PROFILES : EXPERIMENTAL CHECK OF THE DEVIATION FROM THE IMPULSE APPROXIMATION IN GRAPHITE
}

\author{
A. Issolah, J . Chomilier, G. Loupias, B. Levy, Alberto J. Beswick
}

\section{To cite this version:}

A. Issolah, J . Chomilier, G. Loupias, B. Levy, Alberto J. Beswick. CALCULATED COMPTON PROFILES : EXPERIMENTAL CHECK OF THE DEVIATION FROM THE IMPULSE APPROXIMATION IN GRAPHITE. Journal de Physique Colloques, 1987, 48 (C9), pp.C9-847-C9-850. 10.1051/jphyscol:19879151 . jpa-00227263

\section{HAL Id: jpa-00227263 https://hal.science/jpa-00227263}

Submitted on 1 Jan 1987

HAL is a multi-disciplinary open access archive for the deposit and dissemination of scientific research documents, whether they are published or not. The documents may come from teaching and research institutions in France or abroad, or from public or private research centers.
L'archive ouverte pluridisciplinaire HAL, est destinée au dépôt et à la diffusion de documents scientifiques de niveau recherche, publiés ou non, émanant des établissements d'enseignement et de recherche français ou étrangers, des laboratoires publics ou privés. 
JOURNAL DE PHYSIQUE

Colloque C9, supplément au $\mathrm{n}^{\circ} 12$, Tome 48, décembre 1987

\title{
CALCULATED COMPTON PROFILES : EXPERIMENTAL CHECK OF THE DEVIATION FROM THE IMPULSE APPROXIMATION IN GRAPHITE
}

\author{
A. ISSOLAH $H^{*}$ J. CHOMILIER* ${ }^{*}$, G. LOUPIAS****, B. LEVY** and \\ A. BESWICK*** \\ * Laboratoire de Minéralogie-Cristallographie, Universités \\ Paris VI et VII, CNRS UA-09, 4, Place Jussieu, T 16, \\ F-75252 Paris Cedex 05, France \\ * Groupe de Chimie Quantique, Laboratoire de Physico-Chimie du \\ Rayonnement, Bât. 337, Université Paris-Sud, F-91405 Orsay \\ Cedex, France \\ ***LURE, CNRS-CER-MEN, Bât. 209D, Université paris-Sud, \\ F-91405 Orsay Cedex, France
}

RESUME

Pour obtenir les profils compton de valence du graphite, on soustrait des profils experimentaux un profil d'electrons de coeur du carbone soit impulsionnel SCF soit quasi SCF. Les profils de valence ainsi obtenus diffèrent en amplitude 0 environ 2\%. par contre l'anisotropie reste inchangèe.

\section{ABSTRACT}

To ootain the valence compton profiles of graphite, a carbon core electron profile, either impulse SCF or quasi SCF, is subtracted from the experimental profiles. The valence profiles obtained are different by about $2 \%$ in amplitude but the anisotropy remains unchanged.

In solid state physics, the measurements of the Doppler broadening of the inelastically scattered $X$-rays, the compton profiles (CP), are particularly sensitive to the behaviour of the outer, loosely bound conduction or valence electrons. The experimental CP are easily analysed in the Impulse Approximation (IA) assumption. In this case, the total $C P$ is just the sum of all the monoelectronic $C P$ :

$$
]_{\operatorname{tot}}\left(a_{z}\right)=\varepsilon_{i} j_{i}=\sum_{i} \iint\left|\dot{x}_{i}(\vec{a})\right|^{2} d a_{x} d a_{y}
$$

where $q_{z}$ is the projection of the electron momentum on the scattering vector $\vec{k}$. $x(\vec{a})$ is the Fourier transform of the wave function of the target electron i; no care is taken of the final state. Only this total profile is measured: so, in order to compare the experimental directionnal compton profile (DCP) to the calculated one, it is necessary to subtract a calculated core profile from the first one, (Fig.1), because most of the solid state calculations lead only to the valence and conduction profiles.

Recent measurements on graphite are performed at LURE-OCI with an incident energy of $12858 \mathrm{eV}$ and a scattering angle of $135^{\circ}$. The transferred energy at the Compton peak is only twice the ionisation threshold of the is carbon electron. Under these conditions, although the Impulse Approximation may be valid for the loosely bound valence electrons, this is not the case for the core ones. So. in order to analyse the experimental valence $C P$, the deviation from the IA has to be taken into account. 


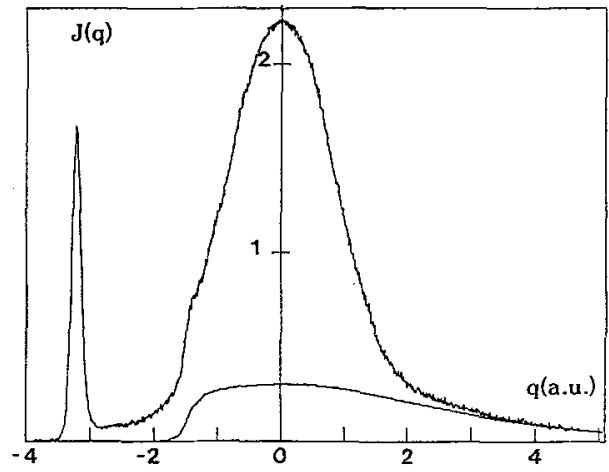

Fig. 1. Total experimental directionnal profile $(\vec{x}$ perpendicular to $\vec{c}$, in graphite and the core Impulse one that fits the total one at large $q_{z}$.

The comparison between the experimental profiles and the calculated ones. leads to a discrepancy that might be decreased by an improvement either in the calculations (1) or in the data treatment. In this comparison, we noticed that the experimental anisotropy (i.e the difference between two DCP) is slided with respect to the calculated one (2). This might arise either from the core $\mathrm{sp}^{2}$ hybridization, or from the deviation to the. IA To have an order of magnituoe of the sp hybridization effect on graphite, we have calculated the molecular orbitals of the radical $\mathrm{CH}_{3}$, and it was found it is similar to the carbon $1 \mathrm{~s}$ orbital, slightly perturbed by hydrogen sites. Compton profiles calculated within the IA along the $\mathrm{C}-\mathrm{H}$ axis, and two directions perpendicular, only reveals deviations (in amplitude) less than the statistical accuracy at the center of the profile.

Since the coupling with the electromagnetic field is weak, we may calculate the CP by using the lowest order $80 \mathrm{rn}$ approximation.

Then, in the independent eiectron and frozen core approximations, the CP

- as in the impulse case - is a sum of one electron contributions:

$$
J_{\text {tot }}=\Sigma_{i} \Sigma_{f}\left|\left\langle\varphi_{f}\left|\exp \left(i \vec{K}_{I}\right)\right| \varphi_{i}\right\rangle\right|^{2} \delta\left(e_{f}-e_{i}-\Delta E\right)
$$

where $i$ and $f$ refer to initial and final states; e the energy of the electronic state: $\Delta E$, the energy transferred from the photon to the electron. oifferents approaches have been presented to explain the deviation to the IA in the case of Compton scattering (3) or electron scattering (4).

The difficulty in calculating the $C P$ using Eq.2 arises from the final state $\varphi_{f}$ of the electron. To compute the core profile of the carbon. we have evaluated numerically $\varphi_{f}$ using the SCF potential of the is state without exchange terms. This is an improvement compared to a coulomb wave final state (5).

This quasi SCF final state leads to a compton core profile notably different (Fig.2) compared to the impulse one: - the maximum of the $C P$ is at $q_{\max }=-0.1$ u.a (this deviation is called the
"Compton defect");

- the principal discrepancy comes from the amplitude of the maximum of CP which is 13\% lowest than the impulse one (Fig.3).

These two effects can be due respectively to:

- $q_{\text {max }}$ which is related to some mean value $v(\bar{F})$ of the potential experienced by the electron in its final state;

- the variation of $V(r)$ around $\bar{r}$ is large and goes from $-z / r$ (z nuclear charge) for $r$ close to zero, to $-1 / r$ for $r$ close to $r_{\max }\left(0, r_{\max }\right.$ are the integration boundaries of the transition matrix element?. max 


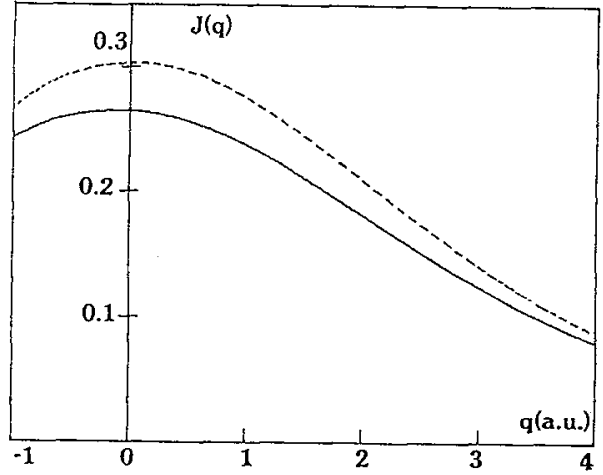

Fig.2. Compton core profile in graphite: OSCF (-) I,IA1-..-1.

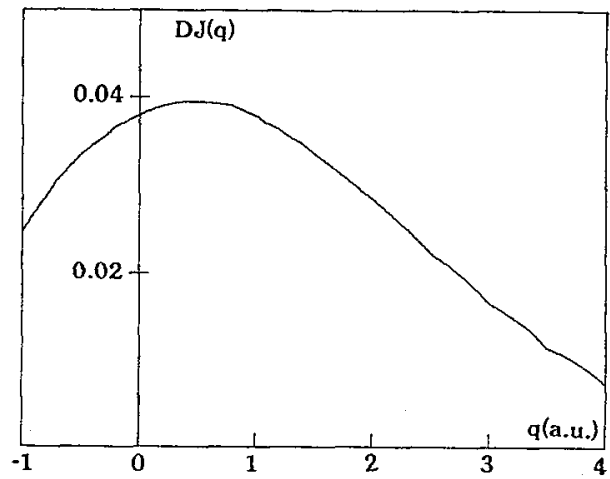

Fig.3. Difference bétwien IA and OSCF core profiles.

The experimental valence for conductionl compton profile obtained by the subtraction of this OSCF cole profile from total one is :

- Symmetric. since the OSCF CP is flat and very slightly asymmetric about $a_{\text {, }}=0$; the oisplacement of the valence compton Peak is negligible lor cannot be evazuated because of the statistics of the experimental resultsl. So the anisotropy of the valence electron is unchanged when subtracting core oSCF profile or impulse one:

- Decreased, in emplitude, near $Q_{2}=0$ and consequently increased (for normalization reasons) at large $a_{z}$ as snown on figure 4.

Therefore, the so-corrected valence profile leads to an enhancement of the difference with the calculated one as illustrated on the figure 5 . This oiscrepancy is discussed in term of correlation effects $(5)$.

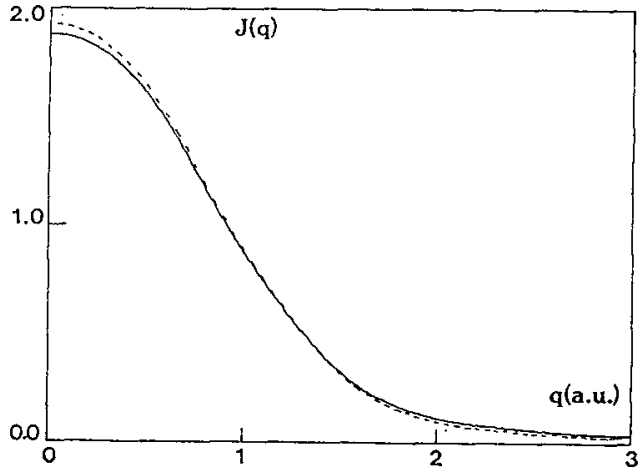

Fig.4. Experimental valence CP after substracting : OSCF core profile (-):

IA core profile $(---)$. The error bat is the order of magnitude of the thickeness of of the line.

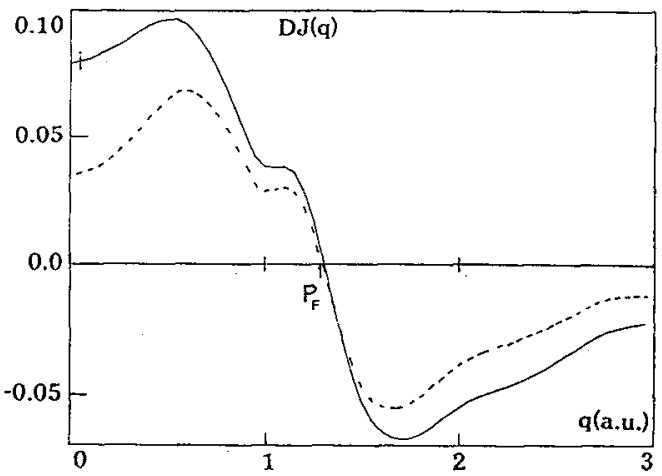

Fig.5. Difference between: calculated valence profile(1) ano experimental one correted with OSCF core profile (-) and IA core profilel-al. 
In the case of carbon atom the overlaps between the QSCF $\varphi_{f}$ and $\varphi_{1 s} \cdot \varphi_{2 s}$. $\varphi=2 p$; atomic orbitals are respectively $6.810^{-6}, 1.210^{-6}, 1.610^{-3}$ at $q_{2}=q_{\max }$ and decrease with increasing $a_{z}$; so the exchange terms are probably not very important. Although the core graphite have the same behaviour than the is carbon one, this is not the case for the valence electrons. So, to evaluate the coulombic part of the potential in graphite, one should use Bloch waves describing valence electrons instead of atomic orbital $(2 \mathrm{~s}, 2 \mathrm{p})$. A question then arises wether this latter description changes the atomic potential and thus the core profile for graphite.

\section{REFERENCES}

1. M.Y. CHOU, Marvin L. COHEN and Steven 6. LoUIE, Phys. Rev. B33, (1986) 6519

2. G. LOUPIAS, J. CHOMILIER and D. GUERARD, J. Physique lett. $45(1984)(-301-306$

3. P.E. EISENBERGER and P.M. PLATZMANN. Phys. Rev. A2 (1970) 415

L. MENDELSOHN and V.H. SMITH in compton scattering. The investigation of electron momentum distribution, edited by B. Williams (MC Graw Hill, 1977, G.B.)

R. CURRAT, P.D. DE CICCO and ROW KAPLOW: Phys, ReV. B3, $(1971), 243$

4. C. TAYARD, M.C. DAL CAPELlO, F. GASSER, C. DAL CAPELLO and H. F. WELLENSTEIN; PHÝS.REV. AZZ. (19B3) 199 .

M.J. BROTHERS and R.A. BONHAM, J.Phys. B : At.Mol. Phys. 17 (1984) 4235 .

5. A. ISSOLAH, B. LEVY, A. BESWICK and G. LOUPIAS to be published

6. A. ISSOLAH, J. CHOMILIER, Y. GARREAU, G. LOUPIAS, "Electron correlation in metals evioenced by compton scattering". in this conference. 